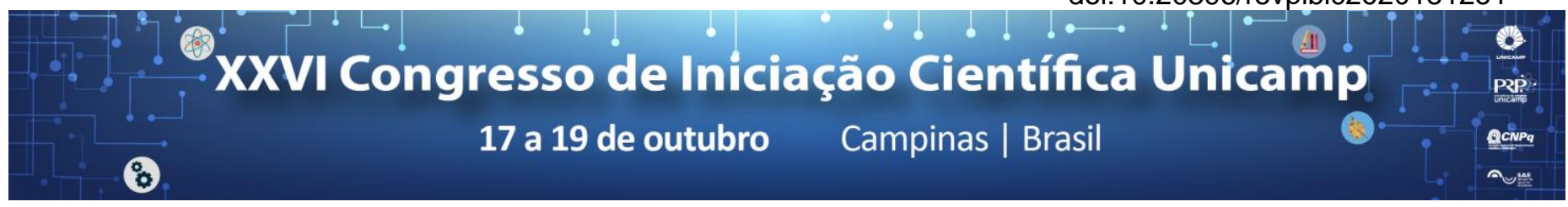

\title{
Descrição do grito de agonia de Ceratophrys aurita
}

\section{Ronaldo M. N.Santos*, Luís Felipe Toledo}

\section{Resumo}

Os anuros emitem sons em diferentes contextos sociais. O grito de agonia é o tipo de vocalização mais comum dentro do contexto defensivo. Em Ceratophrys aurita o grito de agonia consiste em um canto simples, harmônico, potente e emitido continuamente de forma pulsátil.

\section{Palavras-chave:}

Grito de agonia, Bioacústica, Anuros.

\section{Introdução}

A sons emitidos por anuros destacam-se como um importante mecanismo de comunicação dentro de uma comunidade, seja a nível intra ou interespecífico ${ }^{1}$. A diversidade e conspicuidade das vocalizações destes animais tem chamado a atenção de cientistas que estudam o comportamento dos anuros, sua ecologia e a bioacústica dos seus cantos. Os sons emitidos por anuros podem ser categorizados de acordo com três diferentes contextos sociais: reprodutivo, agressivo ou defensivo ${ }^{2}$. No contexto defensivo, o grito de agonia é o tipo de vocalização mais frequente, emitido tanto por machos quanto por fêmeas e jovens ${ }^{3}$. Esse grito é emitido quando um indivíduo está sob ataque ou abordagem de um predador em potencial, sendo caracterizado por altos gritos ou sons sibilantes com a boca aberta que, provavelmente, tem a função de assustar ou intimidar o predador. A similaridade estrutural do grito de agonia entre as espécies faz com que ele não seja, comumente, usado para fins taxonômicos; apesar disso, pode ser útil em casos extremos ${ }^{4}$.

Neste trabalho descrevemos o grito de agonia de Ceratophrys aurita (Anura, Ceratophryidae), espécie rara, popularmente conhecida como Sapo-Intanha, que vive em pequenas cavidades ou galerias, naturais ou escavadas, no solo em áreas florestadas dos estados costeiros do Brasil, entre o Rio Grande do Sul e Bahia, e Mina Gerias.

\section{Resultados e Discussão}

Foram analisadas duas gravações depositadas na Fonoteca Neotropical Jacques Vielliard, Unicamp. A primeira (FNJV 32127) gravada no município de Teresópolis-RJ em 1967 por Bertha Lutz, originalmente gravada em uma fita magnética em velocidade de 19 $\mathrm{cm} / \mathrm{s}$; digitalizada em uma placa de som MOTU Ultra Lite MK3 a $96 \mathrm{kHz}$ de taxa de amostragem, e 24 bits de resolução (gravação feita de um animal em cativeiro). A segunda gravação (FNJV 36466) foi gravada no município de Linhares-ES em 2017 por Luís Felipe Toledo, com um TASCAM DR-40 a $48 \mathrm{kHz}$ de taxa de amostragem e 24 bits de resolução. As análises foram feitas no Raven Pro 1.5, com as seguintes configurações para os espectrogramas: brilho 48 , contraste 88 , FFT 512, janela tipo Hann, e sobreposição 50\%.

Na primeira gravação (FNJV 32127) foram analisadas as seguintes variáveis: duração do canto (medida manualmente no oscilograma e adicionalmente com a medida "Duração 90\%"), menor frequência (com a medida "Frequência 5\%"), maior frequência (com a medida "Frequência 95\%") e frequência dominante (com a medida "Máxima frequência"). Na segunda gravação (FNJV 36466) foram analisadas apenas medidas no espectrograma referentes aos harmônicos visíveis no canto, são elas: frequência dominante (com a medida "Máxima frequência"), maior frequência (com a medida "Frequência 95\%") e menor frequência (com a medida "Frequência $5 \%$ ").

Tal como em outras espécies da mesma família $C$. aurita, emite o grito de agonia enquanto realiza movimentos súbitos de boca aberta tentando morder o agressor ${ }^{5}$. Consiste em um canto simples, possui uma única nota com harmônicos, emitido continuamente, com duração média de $45,6 \mathrm{~s}$, de forma pulsátil. A frequência mínima média foi $1,17 \mathrm{kHz}$, a máxima $7,41 \mathrm{kHz}$ e a dominante $1,88 \mathrm{kHz}$. O número de harmônicos visíveis foi de 8 dentro da faixa entre a frequência mínima e máxima do canto (dentro dos $90 \%$ de energia do canto). O primeiro harmônico tem frequência dominante de 1,31 $\mathrm{kHz}$ e o segundo, o harmônico dominante, de $2,63 \mathrm{kHz}$, com maior frequência de $2,72 \mathrm{kHz}$ e a menor $1,72 \mathrm{kHz}$.

\section{Conclusões}

Apesar de o grito de agonia não ser recomendado para o uso na taxonomia, é necessário considerar que este tipo de vocalização ainda é pouco gravado e relatado 4 , fazendo-se necessário aumentar o número de gravações e análises desta categoria de vocalização, que podem ser necessárias em estudos onde a descrição ou distinção de espécies não conte com os tipos mais comuns de vocalizações.

\section{Agradecimentos}

Aos meus colegas de laboratório, em especial a Camila Zornosa-Torres, Lucas Forti e Simone Dena pelas aulas de bioacústica. A Fonoteca Neotropical Jacques Vielliard pela disponibilização dos arquivos. Ao The Cornell Laboratory of Ornithology por fornecer a licença do software Raven.

\footnotetext{
1 Valetti, J. A.; Salas, N. E. e Martino, A. L. Rev. Biol. Trop. 2013, 61 (1), 273 280 .

2 Toledo, L. F; Martins, I. A.; Bruschi, D. P.; Passos, M. A.; Alexandre, C. e Haddad, C. F. B. Acta ethologica. 2014, 18, 87-99.

3 Toledo, L. F. e Haddad, C. F. B. South American Journal of Herpetology. 2009, 4(1), 25-42

${ }^{4}$ Köhler, J.; Jansen, M.; Rodríguez, A.; Kok, P. J. R.; Toledo, L. F.; Emmrich

M.; ... Vences, M. Zootaxa. 2017, 4251(1), 1-124.

${ }^{5}$ Lescano, J. N. Journal of Natural History. 2011, 45, 2929-2938.
} 